Revista Destaques Acadêmicos, Lajeado, v. 10, n. 3, 2018. ISSN 2176-3070

DOI: http://dx.doi.org/10.22410/issn.2176-3070.v10i3a2018.1729

http://www.univates.br/revistas

\title{
PEELING DE ÁCIDO SALICÍlICO NO TRATAMENTO DA ACNE
}

\author{
Chaiani Rogeri ${ }^{1}$, Giovana Sinigaglia ${ }^{2}$
}

Resumo: A acne é uma patologia crônica, multifatorial e universal. Na maioria das vezes, aparece na adolescência e pode estender-se à vida adulta. Para iniciar qualquer escolha terapêutica é preciso levar em conta um conjunto de lesões, as quais, isoladas ou em conjunto, definem as características e o grau de intensidade da acne. O tratamento é de extrema importância para reduzir sua gravidade, seu potencial para recorrência, formação de cicatrizes e repercussão psicossociais, contribuindo para melhora da qualidade de vida. Para o presente artigo, foi realizada uma pesquisa de artigos por meio de revisão de literatura entre os meses de junho a dezembro de 2017, nas bases de dados científicas incluindo literaturas publicadas no período de 2000 a 2017, através do qual foi verificada a utilização de ácido salicílico enquanto peeling químico. Conclui-se que o tratamento com ácido salicílico mostra grande eficácia no tratamento de acne por meio de sua ação queratoplástica, queratolítica e bacteriostática. É importante destacar que o ácido salicílico age como esfoliante químico, promovendo a renovação celular, agindo tanto na prevenção quanto no tratamento de comedões, pápulas e pústulas.

Palavras-chave: Acne. Ácido salicílico. Peeling.

\section{Introdução}

A acne é uma dermatose que afeta regiões com grande concentração de folículos pilossebáceos, como a face e a região superior do tronco. Normalmente, sua aparência é branda e transitória, podendo evoluir para formatos mais graves. A acne apresenta diversos fatores que podem determinar seu desenvolvimento e sua gravidade, como o estresse, a ansiedade, a alta umidade, a fricção excessiva da pele, as alterações hormonais e os medicamentos. Além

1 Farmacêutica diplomada pelo Centro Universitário UNIVATES, agora Universidade do Vale do Taquari - Univates. Possui pós-graduação lato sensu em Atenção Farmacêutica e Farmácia Clínica pelo IPOG - Instituto de Pós-graduação e em Estética e Saúde pela Univates. Atua como farmacêutica no município de São José do Herval.

2 Fisioterapeuta. Coordenadora do Curso de Estética e Cosmética e Coordenadora da PósGraduação em Estética e Cosmética da Univates. 
desses, é importante lembrar que o componente genético pode influenciar na conformação do folículo, facilitando a obstrução (BRENNER et al., 2006; PICOSE et al., 2016; NETO et al., 2015; AL TALIB et al., 2017).

Segundo Schmitt et al. (2011), a acne causa impacto psicossocial, além de deixar cicatrizes inestéticas permanentes. Ela acomete aproximadamente $80 \%$ da população jovem - entre 12 a 18 anos de idade -, podendo ocorrer em outras fases da vida, abordando igualmente homens e mulheres, sendo mais rigorosa em pessoas do sexo masculino.

O quadro clínico é estabelecido de acordo com o tipo de lesão, que pode ser classificada em diversos graus. Algumas pessoas podem até mesmo desenvolver manifestações mais graves da disfunção, com ocorrência de cicatrizes, manchas e alterações na superfície da pele (DEUSCHLE et al., 2014; BAGNOLI et al., 2010).

Nesse contexto, a terapêutica por ácidos tem sido preconizada como primeira linha de tratamento a fim de evitar a dependência do uso de medicamentos e os seus possíveis efeitos colaterais (PANTOJA, 2013).

O ácido salicílico é amplamente utilizado no tratamento da acne. Ele tem ação levemente antisséptica, queratoplástica e, principalmente, queratolítica, quando usadas em altas concentrações. Sua ação queratolítica (acima de $3 \%$ ) permite a promoção de um peeling superficial, tendo impacto apenas na epiderme, sem atuar nas camadas mais profundas da derme, o que faz dele um peeling seguro. Ele age na diminuição da coesão dos corneócitos, desobstruindo os folículos pilossebáceos e, a partir disso, é realizada a renovação celular (FONSECA et al., 2012).

\section{Referencial teórico}

\subsection{Acne vulgar}

A acne é uma doença inflamatória que resulta a oclusão dos folículos sebáceos devido à quantidade excessiva de sebo produzida pelas glândulas sebáceas, cujo estímulo é mediado por hormônios andrógenos. Também contribui para o desenvolvimento de lesões como o excesso de descamação das células epiteliais nas paredes dos folículos, a hiperqueratinização decorrente da hiperproliferação dos queratinócitos e/ou a separação inadequada dos corneócitos ductais e sua consequente inflamação. Promove ainda o aumento da proliferação de Propionibacterium acnes, que hidrolisa as triglicérides do sebo por meio de esterases, resultando ácidos graxos livres irritantes à parede folicular e induzindo à queratinização (VAZ, 2003; COSTA et al., 2008; BAGNOLI et al., 2010).

A população de Propionibacterium acnes é maior na face e no tronco superior, locais com maior quantidade de lipídeos, indicando relação direta entre a população bacteriana e a seborréia local (COSTA et al., 2008). O acúmulo 
de células e de sebo implica a formação do micromedão, uma lesão microscópica evidente em todos os indivíduos com acne. Em pacientes predispostos a acne, o folículo pilossebáceo se cobre com sebo, queratina e bactérias, formando uma lesão clinicamente aparente. A contribuição relativa desses fatores determina se a lesão será inflamatória ou não inflamatória, podendo ocorrer progressão de um tipo de lesão para outro e até formação cicatricial (PICOSE et al., 2016; MONTAGER; COSTA, 2010; FIGUEIREIDO et al., 2011).

Assim, a acne pode ser classificada como grau 1 caso tenha a presença de comedões, que são cravos pretos e cravos que se juntam com pequenos e raros cistos no rosto. O grau 2 apresenta comedões, pústulas muito raras e pequenos cistos restritos à face. $\mathrm{O}$ grau 3 é bem variável: ora possui inúmeras lesões, ora praticamente demonstra remissão das lesões. Os pacientes de grau 3 apresentam muitos comedões, com pequenas e grandes pápulas, e pústulas espalhadas, mas ainda restrito à face. Há ruptura da parede folicular, com reação inflamatória aos comeócitos e às bactérias, formando os nódulos, clinicamente repleto de pus. Por fim, o grau 4 é atribuído à pacientes que têm muitos comedões combinados com lesões profundas na face e no tronco superior (RAMILI et al., 2012; COSTA, LUBI, 2012).

\section{2 Ácido salicílico}

O ácido salicílico pode ser classificado como um ácido beta-hidroxi, com valor de pKa de 2,8, o que o torna um ácido fraco, solúvel em água e que apresenta atividade anti-inflamatória e antimicrobiana (LEE \& KIM, 2003; SHOU et al., 2009). Possui uma hidroxila no segundo carbono após o agrupamento carboxila (carbono beta), o que pode causar descamação na parte superior das camadas do estrado córneo, além de ativar as células basais e os fibroblastos, melhorando o aspecto da pele (DEUSCHLE et al., 2014; LIKES et al., 2012).

O ácido salicílico é proveniente da casca do salgueiro e é o único membro da família do ácido beta-hidroxi. Recebeu esse nome porque o ácido carboxílico aromático possui um grupo hidroxi na posição beta. É utilizado há muitos anos no tratamento da acne e compõe várias preparações farmacêuticas disponíveis na atualidade. Tem ação esfoliativa e queratolítica, podendo facilmente se infiltrar em camadas pilossebáceas, reduzindo a adesão dos corneócitos. Devido a sua natureza lipofílica, o ácido salicílico tem um forte efeito comedolítico. Afeta a cascata araquidônica, portanto, exibe capacidade anti-inflamatória, tornando-se útil na rápida diminuição do eritema facial (AL TALIB et al., 2017; HANDOG; SINQZON, 2012; VEDAMURTHY, 2004; COSTA; BAGATIN, 2013).

Possui um perfil de segurança muito bom, atóxico e autoneutralizante, com mínima infiltração dérmica. É de baixo custo, de fácil aplicação e tem a capacidade de auto neutralizar-se. Outro benefício do ácido salicílico é seu 
efeito de iluminação na pigmentação pós-inflamatória devido à acne (AL TALIB et al., 2017; HANDOG; SINQZON, 2012).

Os eventos adversos do ácido salicílico são menores e temporários, como a secura e eritema. Sua toxicidade ocorre quando aplicado em grande área devido à absorção sistêmica do ácido e às altas concentrações (AL TALIB et al., 2017).

\subsection{Peeling químico}

O peeling químico também é utilizado no tratamento da acne. É uma técnica que utiliza agentes químicos com aplicação local para estimular a renovação da pele. Tem diversas aplicações clínicas, dentre elas o tratamento da pele facial lesada por problemas como acne, ictiose, melasma e verrugas (HENRIQUES et al., 2007). Caracteriza-se por uma esfoliação acelerada da pele, induzida por agentes cáusticos que provocam dano controlado. A profundidade da aplicação depende de vários fatores, como o tipo de pele, os tratamentos prévios, o local anatômico, o desengorduramento, a técnica de aplicação, os agentes, entre outros (BAGATIN; HASSUN; TALARICO, 2009).

Os peelings químicos podem ser classificados de acordo com o nível de profundidade da necrose tecidual provocada pelo agente esfoliante. $\mathrm{O}$ peeling muito superficial atinge a camada granulosa e córnea, remove o estrato córneo e não cria lesão abaixo do estrato granuloso. O peeling superficial atua somente na epiderme, provoca esfoliação epidérmica, produz necrose da epiderme em todo o estrato granuloso até a camada basal. O peeling médio atinge derme papilar, produz necrose da epiderme e da derme papilar. O peeling profundo atinge a derme reticular, produz necrose da epiderme e da derme papilar, estendendo-se para a derme reticular (BAGATIN; HASSUN; TALARICO, 2009; GUERRA et al., 2013).

O peeling químico tem a sua ação direta sobre a pele e, por isso, é necessário conhecer sua fisiologia, sua anatomia e suas funções para que os resultados de um procedimento antiacnéico sejam satisfatórios e proporcionem segurança ao paciente, minimizando riscos (AKIYOSHI; CAWAHISA, 2009).

Segundo Padova \& Varottui (2007), o ácido salicílico é pouco solúvel em água. Por esse motivo, em solução alcoólica, ele pode ser utilizado como peeling superficial, em concentração de $20 \%$ e $30 \%$, sendo que, quando associado a outros tipos de ácidos, promove melhor resultado.

As contraindicações incluem pacientes com infecção bacteriana, viral ou fúngica ativa, tendência à formação de queloides, dermatite facial, medicamentos fotossensibilizantes, fotoproteção inadequada, gravidez e dificuldade para entender ou seguir orientações fornecidas (KHUNGER, 2008; GUERRA et al., 2013). 


\section{Metodologia}

Foi realizada uma pesquisa de artigos por meio de revisão de literatura. Os artigos selecionados foram publicados na base de coleta de dados: Google Acadêmico, Scielo e Pubmed, no período de 2000 a 2017, com os seguintes descritores: acne, ácido salicílico e peeling.

\section{Resultados e discussão}

O tratamento para acne tem como objetivo manter limpa a face e/ou a região acometida, além de realizar o afinamento do extrato córneo, a fim de diminuir a queratinização folicular, a oleosidade, a contaminação bacteriana e, consequentemente, a inflamação (ALVARES; TABORDA; ALMA, 2012).

Para Vaz (2003), o objetivo do tratamento é prevenir ou tratar lesões, reduzir o desconforto físico provocado pelas inflamações, melhorar a aparência do paciente, prevenir ou minimizar as cicatrizes e evitar o desenvolvimento de efeitos psicológicos adversos.

O tratamento deve iniciar o mais cedo possível para diminuir o estigma e evitar a formação de cicatrizes, cuja terapêutica é mais difícil. Sendo assim, sugere-se procurar um profissional nos primeiros sinais da acne, para que seja aplicado o tratamento adequado. Nesse contexto, os peelings surgem como terapêutica eficaz (PANTOJA, 2013). No entanto, outras considerações, tais como características da pele, área da pele a ser tratada, problemas de biossegurança, tempo de cicatrização e adesão ao paciente, devem ser consideradas para que sejam atingidos os melhores resultados globais (RENDON, 2010).

É essencial iniciar o tratamento com um agente comedolítico, sendo o ácido salicílico o mais indicado, pois reduz a queratose, o eritema e as lesões pustulosas, além de melhorar os processos inflamatórios. Os autores apontam que o ácilo salicílico pode agir como agente de peeling superficial, com a vantagem principal de ter ação controlada e, com isso, o efeito mais previsível (JASINKI; LUBI, 2014). O peeling pode ser repetido uma vez a cada duas semanas, no total 5-6 sessões. É recomendado realizar documentação fotográfica, com consentimento por escrito pelo paciente (VEDAMURTHY, 2004)

O peeling superficial conduziráà esfoliação, queéimportante para redução dos comedões. Além disso, ele tem a capacidade de produzir um processo secativo, diminuindo a probalidade de cicatriz. A regeneração epidérmica pode ser esperada dentro de 3 a 5 dias e a descamação geralmente é aceitável. Os peelings superficiais diminuem a adesão dos corneócitos e aumentam o colágeno dérmico, garantindo um bom método de rejuvenescimento para epiderme e para as camadas cutâneas superiores (RENDON, 2010; VELASCO et al., 2004).

Lee et al (2003) relataram melhoria na acne em 35 pacientes coreanos que apresentavam a doença e que foram tratados com ácido salicílico $30 \%$. A 
redução na contagem de lesões aumentou a medida que houve manutenção do tratamento.

Segundo Padova \& Varottui (2007), o ácido salicílico apresenta ação queratolítica, resultando em rápido rejuvenescimento do extrato germinativo da pele, não ocorrendo qualquer tipo de inflamação ou degeneração do local tratado. Sua indicação para tratamento de acnes comedônicas e pápulopastosas é frequente devido à grande capacidade em promover turnover celular e ser de fácil uso.

Um estudo de Kessler et al (2008) descobriu que ácido salicílico foi eficaz no tratamento da acne vulgar com eventos adversos mínimos. Também mostrou melhora significativa para comedões e pápulas 4 semanas antes do tempo se comparado ao ácido glicólico. O estudo mostrou que a ácido salicílico pode ser usado para todos os estágios da acne ativa devido às suas propriedades anti-inflamatórias e comedolíticas.

\section{Considerações finais}

A acne é uma doença crônica e recorrente que atinge boa parte da população, causando desconforto físico e psicológico. Assim, ressalta-se a importância da abordagem terapêutica em realizar a ação de controle da proliferação microbiana, da hiperceratose, da oleosidade epidérmica e da inflamação.

Verificou-se que o peeling de ácido salicílico é um agente com efeitos satisfatórios devido às características anti-inflamatória, bacteriostática, queratolítica e antimicrobiana, as quais favorecem a diminuição da atividade da glândula sebácea e da queratinização folicular. É importante destacar que também age como esfoliante químico, promovendo a renovação celular, agindo tanto na prevenção quanto no tratamento de comedões, pápulas e pústulas.

\section{Referências}

AKIYOSHI, N. H.; CAWAHISA, V. Peeling químico: utilização e modalidades existentes na medicina estética. (Monografia apresentada à Universidade Tuiuti do Paraná). Curitiba, 2009. AL-TALIB, H., HAMEEDH, A., AL-KHATEEB, A. Efficacy andsafetyof superficial chemical peeling intreatmentofactive acne vulgaris. AnBrasDermatol. 2017; 92 (2): 212-6.

AL-TALIB, Hassanain et al . Efficacy and safety of superficial chemical peeling in treatment of active acne vulgaris. AnBrasDermatol, Rio de Janeiro, v. 92, n. 2, p. 212-216, Mar. 2017. Disponível em: <http:/ /www.scielo.br/scielo.php?script=sci_ arttext\&pid=S0365-05962017000200212\&lng=en\&nrm=iso >. Acesso em 23 Dez. 2017.

ALVARES, D. B; TABORDA, V. B. A; ALMA, J. M. Acne vulgar: avanços na técnica combinada de limpeza de pele associada ao peeling ultrasônico e a fotobioestimulação com LEDs. Salusvita, Bauru, v. 31, n. 1, p. 71-80, 2012. 
BAGNOLI, V. R., FONSECA, A. M., CEZARINO, A. Y. P., FASSOLAS, G., ANTUNES, J., ARIE, A. V. R., BARACAT, E. Tratamento hormonal da acne baseado em evidências. Femina; v. 38, n. 11, nov. 2010.

BAGATIN, E., HASSUM, K., TALARICO, S. Revisão sistemática sobre peelings químicos. Surgical \& Cosmetic Dermatology, vol. 1. 2009, pp. 37-46. Brasil.

BRENNER, F. M., ROSAS, F. M. B., GADENS, G. A.,SULZBACH, M. L., CARVALHO, V. G., TAMASHIRO, V. Acne: um tratamento para cada paciente. Rev. Ciênc. Méd., Campinas, 15(3):257-266, maio/jun., 2006.

COSTA, J. C. C., LUBI, N. C., O ácido retinóico no tratamento da acne. Universidade Tuiuti, 2012.

COSTA, C. S., BAGATIN, E. Evidências sobre o tratamento da acne. Diagnóstico e Tratamento, v. 18, n. 1, 2013.

COSTA, A., ALCHORNE, M. M. A.; GOLDSCHMIDT, M. C. B. Fatores

etiopatogênicos da acne vulgar. AnBrasDermatol, Rio de Janeiro, v. 83, n. 5, p. 451459, Out. 2008.

DEUSCHLE, V. C. K. N., HANSEN, D., GIACOMOLLI, C. M. H., REIS, G.

Caracterização das lesões e tratamentos utilizados na acne. Revista Interdisciplinar de Ensino, Pesquisa e Extensão vol. 3 n.1, 2014.

FIGUEIREDO, Américo et al . Avaliação e tratamento do doente com acne - Parte I: Epidemiologia, etiopatogenia, clínica, classificação, impacto psicossocial, mitos e realidades, diagnóstico diferencial e estudos complementares. RevPortClin Geral, Lisboa, v. 27, n. 1, p. 59-65, jan. 2011.

FONSECA, M. T. B. N., OLIVEIRA, S. P., LUBI, N. C. Os benefícios do peeling de ácido salicílico na acne vulgar. Universidade Tuiuti, 2012.

GUERRA, F. M. R. M., KRINSK, G. G., CAMPIOTTO, L. G., GUIMARÃES, K. M. F. Aplicabilidade dos peelings químicos em tratamentos faciais - estudo de revisão. Braz.J. Surg.Clin. Res.V.4,n.3,pp.33-36 (Set-Nov. 2013).

HENRIQUES, B. G., SOUSA, V. P.,VOLPATO, N. M., GARCIA, S. Desenvolvimento e validação de metodologia analítica para a determinação do teor de ácido glicólico na matéria-prima e em formulações dermocosméticas. Revista Brasileira de Ciências Farmacêuticas - Brazilian Journal of Pharmaceutical Sciences vol. 43, n. 1, jan./mar., 2007.

HANDOG, E. B., SINQZON, I. A. Chemical peels for acne and acne scars in asians: evidence based review. J CutanAesthetSurg, 2012;5:236-46.

JASINSKI, M. C.,LUBI, N. Ação do peeling de ácido salicílico no tratamento de acne. Universidade Tuiuti do Paraná (Curitiba, PR). 2014. 
KESSLER E, FLANAGAN K, CHIA C, ROGERS C, GLASER DA. Comparison of alpha and beta-hydroxyacid chemical peels in the treatment of mild to moderately severe facial acne vulgaris. DermatolSurg. 2008;34(1):45-50.

KHUNGER, N. Standard guidelines of care for chemical peels. Indian J Dermatol Venereol Leprol 2008;74, Suppl S1:5-12.

LEE HS, KIM IH. Pele de ácido salicílico para tratamento de acne vulgar em pacientes asiáticos. Dermatol Surg. 2003; 29: 1196-1199.

LIKES, Joana A. K.,AMARAL, Franciele A., DEON, Keila C. Ação do peeling de ácido salicílico a $\mathbf{2 0} \%$ associado ao uso domiciliar de peróxido de benzoíla no tratamento de acne vulgar. Volume 4. Número 21. Novembro/Dezembro 2012.

MONTAGNER, S., COSTA, A. Diretrizes modernas no tratamento da acne vulgar: da abordagem inicial à manutenção dos benefícios clínicos. SurgCosmetDermatol. 2010; 2(3):205-13. 2010.

NETO, E. M. R., BARROS, K. B. N. T., JUNIOR, F. J. G., LOBO, P. L. D., FONTELES, M. M. F. Abordagem terapêutica da acne na clínica farmacêutica. Boletim Informativo Geum , v. 6, n. 3. P. 59-66 jul./set. 2015.

Padova MP, Varotti CI. Peelingchimicinell' acne. Tese de doutorado do XIX ciclo de ciências dermatológicas da Universidade Degli Studi di Bologna - Alma MaterStudiorum. 2007. Disponível em: <http:/ /amsdottorato.cib.unibo.it/587/1/ tesi_de_padova.pdf>. Acesso em: 22 de dezembro de 2017.

PANTOJA, R. N. S., MEJIA, D. P. M. Os principais ácidos utilizados no tratamento da acne vulgar: uma revisão de literatura. Faculdade Ávila. 2013.

PICOSE, F. R., BONATTO, K. M., HASSUN, K. M., TALARICO FILHO, S., AZULAY, D. R., BAGATIN, E. Tratamento da acne vulgar moderada a grave com isotretinoína oral similar ao produto referência. SurgCosmetDermatol 2016;8(2):121-7.

RAMILI, R., MALIKI, A. S., HANI, A. F. M., JAMIL, A. Acne analysis, grading and computational assessment methods: an overview. SkinResearchand Technology 2012; 18: $1-14$

Rendon MI, Berson DS, Cohen JL, Roberts WE, Starker I, Wang B. Evidence and considerations in the application of chemical peels in skin disorders and aesthetic resurfacing. J ClinAestheticDermatol. 2010;3:32-43.

SCHMITT, J. V; TAVARES, M; CERCI, F. B. Mulheres adultas com acne apresentam maior risco de elevação de triglicerídeos ao uso de isotretinoína oral. An. Bras. Dermatol., Rio de Janeiro, v. 86, n. 4, Aug. 2011.

SHOU, M.; GALINADA, W.; WEI, Y.; TANG, Q.; MARKOVICH, R.J.; RUSTUM, A.M. Development and validation of a stability-indicating HPLC method for simultaneous determination of salicylic acid, betamethasone dipropionate and their 
related compounds in Diprosalic Lotion ${ }^{\circledR}$. Journal of Pharmaceutical and Biomedical Analysis, v. 50, p. 356-361, 2009.

SILVA, A. M. F., COSTA, F. P., MOREIRA, M. Acne vulgar: diagnóstico e manejo pelo médico de família e comunidade. Bras. Med. Fam. Comunidade. 2014;9(30):54-63.

TAGLIARI, M. P. Desenvolvimento de nanopartículas de quitosana e alginato de sódio para incorporação de ácido glicirrízico, ácido salicílico ou cafeína visando liberação tópica. Florianópolis, 2012.

VAZ, A. L.; Acne vulgar: bases para o seu tratamento. RevPortClin Geral 2003;19:56170.

VEDAMURTHY, M. Cascas de ácido salicílico. Indian J DematolVenereolLeprol 2004; 70: $136-8$.

VELASCO, Maria Valéria Robles et al . Rejuvenescimento da pele por peeling químico: enfoque no peeling de fenol. An. Bras. Dermatol., Rio de Janeiro, v. 79, n. 1, p. 91-99, Feb. 2004. Disponível em: <http:/ / www.scielo.br/scielo.php?script=sci arttext\&pid=S0365-05962004000100011\&lng=en\&nrm=iso >. Acesso em: 22 Dez. 2017.

ZANELATO, Tiago Pina et al. Acne fulminans incapacitante. An. Bras. Dermatol., Rio de Janeiro, v. 86, n. 4, supl. 1, p. 9-12, Aug. 2011. Disponível em: <http:/ / www. scielo.br/scielo.php?script=sci_arttext\&pid=S0365-05962011000700001\&lng=en\&nrm= iso>. Acesso em: 20 Dez. 2017. 